\title{
Beyond performance and protocols: early responders' experiences of multiple accountability demands in the response to the 2015 Nepal earthquake
}

\author{
Nimesh Dhungana LSE Fellow in Qualitative Methods, Departments of Methodology and \\ International Development, London School of Economics and Political Science, United \\ Kingdom, and Flora Cornish Associate Professor in Research Methodology, Department of \\ Methodology, London School of Economics and Political Science, United Kingdom
}

Although critics have long questioned the push for professionalised and performance-driven accountability in the humanitarian sector, the matter is largely treated as a 'back office' issue of standards, guidelines, and processes. Scant attention is paid to the accountability demands experienced by early responders to disasters. Set in the contested climate of the emergency response to the earthquake in Nepal on 25 April 2015, and drawing on interviews with 15 early responders, this paper reveals three forms of accountability demands: (i) accountability as compliance; (ii) accountability as the object of government regulation; and (iii) accountability as public opposition and interrogation. Beyond the performance-centric, nongovernmental organisation-driven understanding of accountability, early responders to the earthquake experienced multidirectional accountability demands, not only from donors and beneficiaries, but also from the national government and wider public. Engaging with public criticism is a significant feature of early responders' responsibility that warrants further consideration by the humanitarian community.

Keywords: accountability, earthquake, humanitarian aid, Nepal, public criticism, responders

\section{Introduction}

The international humanitarian sector has made steady progress over the past two decades in consolidating and expanding its vision of humanitarian accountability, evident in a range of protocols and practices intended to improve the effectiveness, appropriateness, and harmonisation of humanitarian aid (The Sphere Project, 2004; Humanitarian Accountability Partnership, 2010; CHS Alliance, Group URD, and the Sphere Project, 2014). Critical scholarship has raised concerns about the bureaucratising and depoliticising effects of universal protocols and standards, and the unequal North-South power relations that they 
tend to produce (Hilhorst, 2002; Slim, 2002; Tong, 2004; Barnett, 2005, 2013; Stein, 2008; Everett and Friesen, 2010). Recent empirical evidence, although limited, has found that current accountability practices, with their intensive focus on results and benchmarks, have, for instance, impeded local aid workers' efforts to engage in crisis-affected communities (Makuwira, 2006; Daly and Brassard, 2011), and discouraged open communication and collaboration with other non-governmental organisations (NGOs) (Schuller, 2012), given their focus on upward accountability to donors at the cost of downward accountability to communities (Taylor, Tharapos, and Sidaway, 2014).

While accountability is a major object of reform within contemporary humanitarianism, what it means and what it takes to be accountable in a humanitarian crisis context remain a puzzle (Raju and da Costa, 2018). With notable exceptions (Fernando and Hilhorst, 2006; Hilhorst and Jansen, 2010; Taylor, Tharapos and Sidaway, 2014), current scholarship on accountability largely concentrates on theoretical critiques of accountability discourse propagated by and involving the mainstream humanitarian sector, with a paucity of empirical evidence regarding the field-level experiences of early responders in pursuing accountable humanitarian action. This paper seeks to address this gap in the existing literature.

The study is set in the contested climate of the emergency response triggered by the earthquake in Nepal on 25 April 2015. It draws on 15 in-depth interviews with a mixture of early responders, representing the government, NGO, and civil society sectors, who, by virtue of their societal position or formal affiliation, or de facto, found themselves variedly responding to the disaster. Through an analysis of their experience of confronting multiple accountability demands, the paper argues that responding to them amounts to more than adhering to technical standards of performance, it also requires navigating the politically fraught environment of humanitarian response. Beyond performance and protocols, the paper investigates how attention to public-centric accountability demands has implications for the effectiveness of aid delivery and humanitarian performance, as the process may identify problems, point to solutions, and insist on fairness of operations.

The next section of the paper introduces the context of accountability demands in the wake of the earthquake, followed by a discussion of the two major modes of accountability (performance-based and public-centric), which sets the conceptual context. The subsequent empirical section presents the early responders' experiences, the implications of which for the practice of humanitarianism are discussed in the conclusion. 


\section{The 'Great Earthquake' and accountability demands}

A major earthquake, measuring $7.8 \mathrm{M}_{\mathrm{w}}$ on the moment magnitude scale, struck Nepal at 11:56 (local standard time) on Saturday, 25 April 2015. It created an unprecedented humanitarian crisis, resulting in more than 8,790 deaths, injuring in excess of 22,300 people, and affecting the lives of an estimated eight million individuals, almost one-third of the country's population (Government of Nepal, National Planning Commission, 2015, p. XI). Popularly known as the 'Great Earthquake' (Mahabhukampa), it not only laid bare the unpreparedness of the Government of Nepal (GoN) and humanitarian agencies, but also it thrust upon the nation renewed imaginaries of reconstruction and development, captured in the popular slogans of 'building back better' and 'resilient Nepal' (Government of Nepal, National Planning Commission, 2015; United Nations Development Programme, 2015, p. 1).

The emergency response to the disaster occurred in a fraught environment, with affected populations, media representatives, and civil society activists accusing the GoN and aid actors of a sluggish reaction, embezzlement, and hoarding assistance resources (Adhikari, 2015; Harris, 2015). Protests and demonstrations were reported in several parts of the country, including in the capital city, Kathmandu (Adhikari, 2015; Sharma and Adkin, 2015; Siegler, 2015). In one controversial incident, affected communities from Nuwakot District, a significantly affected area in the then Central Development Region, seized a truck loaded with galvanised zinc sheets meant for temporary shelters, alleging that the incumbent Finance Minister, Ram Sharan Mahat, was guilty of corruption; a charge that he vehemently denied (Adhikari, 2015). In Sindhupalchowk, another badly hit and highly impoverished district, angry locals were reported to have blocked a convoy of army vehicles transporting relief materials, sparking a tense situation between locals and the military (Sharma and Adkin, 2015). Citizens also protested outside the Parliament in Kathmandu, demanding improved transport services to attend to family members (Sharma and Adkin, 2015).

Amidst the seemingly chaotic emergency response, the GoN initiated the controversial 'one-window' policy, which sought to centralise rescue and relief aid under the bureaucracy of the central government (Giri, 2015). This decision, in turn, was widely criticised by activists and the Nepali diaspora. A joint statement issued on 30 April 2015 by 36 civil society organisations based in Kathmandu urged the government to reverse its decision, while underlining that it should not use the pretext of emergency management to curtail the rights of the people (NGO Federation of Nepal et al., 2015). Others actors, such as the National Human Rights Commission (2015), warned the government not to inhibit 
citizens' right to information, and demanded transparency in relation to aid. Opposition parties and parliamentarians launched aid monitoring activities in several districts and criticised the response for failing to reach the most deprived and powerless people (Jayashi, 2015). The Nepali diaspora utilised social media and online campaigns to question the competence and trustworthiness of the GoN in handling the disaster. One change.org (2015) petition that quickly amassed 18,100 signatures sought direct intervention by Transparency International, the national Commission for Investigation of Abuse of Authority (CIAA), and the United Nations (UN), alleging not just corruption by political leadership by 'not mobilizing the funds received as earthquake relief', but also 'interfering with and delaying humanitarian assistance'.

The GoN, in turn, publicly committed itself to transparency, accountability, and coherence in the delivery of aid (Giri, 2015; Paudyal, 2015). The website of the Prime Minister's Disaster Relief Fund, serving as a gateway to information on a national humanitarian crisis, was reorganised to include information on the government's actions. In response to the questions about corruption in aid delivery, Prime Minister Sushil Koirala stated that anyone found to be misusing the rescue and relief fund would be 'jailed' (The Rising Nepal, 2015).

In sum, in addition to the human and physical devastation wrought by the earthquake, accountability became a major aspect of controversy and public concern. It is in this context that the early responders to the disaster carried out their work. The main goal of this paper is to understand their experience of accountability demands during an emergency response to a humanitarian crisis. Current conceptualisations point to two different sources of accountability demands: (i) performance-based accountability spearheaded by the international aid sector; and (ii) public-centric accountability demanded by the public. Each is discussed below to frame the analysis.

\section{Performance-based accountability}

The matter of humanitarian accountability attained global prominence in the mid-1990s, particularly following the genocide in Rwanda in April-July 1994, when the humanitarian community faced major criticisms for mismanagement and performance failures (Hilhorst, 2002; Buchanan-Smith, 2003; Barnett, 2005). The international community's response was to spawn professional standards and charters for humanitarian action, intended to set principles to which humanitarian organisations could be held accountable (Hilhorst, 2002). 
This approach is termed 'performance-based accountability', meaning a focus on performance, effectiveness, and efficiency in relation to the delivery of humanitarian aid, particularly operations involving NGOs from the Global North (Slim, 2002). Accountability under this conceptualisation mainly involves: (i) the establishment of universally applicable performance standards; and (ii) monitoring and evaluating, and learning from humanitarian action.

This form of accountability is subject to three principal critiques. First, the suitability of universal standards of humanitarian aid is contested, as they are seen to favour the interests of Northern NGOs and their technical experts at the expense of the values and priorities of Southern aid actors and the rights of beneficiaries (Dufour et al., 2004). Concerns have also been raised that such standards result in rigidity or inaction on the part of humanitarian actors, if adherence to them is deemed unrealistic in a specific crisis situation (Tong, 2004; Keen, 2007), while promoting de-contextualised and de-politicised responses to humanitarian crises that are removed from local realities (Davis, 2007, p. 14; Barnett, 2013).

Second, it has been asserted that the performance-based approach leads to simplification and instrumentalisation of accountability, with its emphasis on monitoring and evaluation of the effectiveness of humanitarian NGOs, concealing politically contentious topics such as donor accountability, and public disclosure of performance (Everett and Friesen, 2010). An extreme spotlight on NGO performance, learning, and measurement, in turn, undermines 'politically sophisticated self-examination of [aid agencies'] interventions' (Middleton and O'Keefe, 1997, p. 158) and their learning from failures (Keen, 2007). Newer practices such as beneficiary feedback mechanisms, or grievance handling systems, are limited to realising the immediate project aspirations of mainstream NGOs (Krause, 2014), often promoting self-evaluation and -censorship within such efforts, while leaving little opportunity for actual beneficiaries of aid to evaluate critically the performance of aid actors and to sanction in the event of underperformance (Pérouse de Montclos, 2012).

Third, an excessive focus on Northern humanitarian NGOs as the key object and subject of humanitarian accountability is problematic because it negates the growing involvement of state actors in setting agendas and regulating and overseeing the humanitarian response (Stein, 2008; Coyne, 2013), as well as the strategies that they deploy in responding to, or deflating, disaster-induced accountability demands (Boin, McConnell, and 't Hart, 2008). Performance-based logic also overlooks the involvement of informal aid workers, or 'new humanitarians', such as activists, independent volunteers, and members of the diaspora 
community, the private sector, and the media (Hilhorst and Jansen, 2010; Sezgin and Dijkzeul, 2016), who are increasingly staking claims in humanitarian responses.

Taken together, the above exposes the limitations of current discussions and practices concerning performance-based, NGO-driven accountability. They fail to pay sufficient attention to the plural and political nature of accountability claims and counterclaims that emanate in the disaster context. Public-centric accountability represents an alternative approach that stands to address the inadequacies of performance-centric accountability.

\section{Public-centric accountability}

The public-centric view of accountability may be accredited to the pioneering work of Amartya Sen, who contended that public voice and criticism play a critical role in compelling powerholders to respond to a looming disaster (Drèze and Sen, 1989; Sen, 1999). India's success in averting large-scale famine, for instance, is attributed to the democratic opening and the environment of public scrutiny that ensued after its independence from the United Kingdom on 15 August 1947 (Sen, 1999).

Although Sen's work on the value of democracy and public criticism centres primarily on the study of hunger and famine, scholars have noted that public criticism and media scrutiny in the wake of the Rwandan crisis in the 1990s played a vital part in propelling contemporary accountability-related reforms in the humanitarian sector (Hilhorst, 2002, Buchanan-Smith, 2003). The value of public and media scrutiny in checking the potential abuse of power by a national government and aid workers is acknowledged (Jalali, 2002; Mizohata, 2011; Roddy, Strange, and Taithe, 2015). Media and civil society have also been found to act as 'warning sensors' vis-à-vis state excesses in the face of major disasters (Jalali, 2002, p. 130). The proliferation of new technologies and social media platforms has further enhanced the possibility for public scrutiny of aid workers. According to Donini and Walker (2012, p. 262), this 'can become a formidable tool for accountability, responsibility and transparency; empty promises, sloppy programming, shady deals, but also successful programmes will be easier to document'.

The potential of public voice to command a response from powerholders is reinforced by a recent scholarly movement in the area of social accountability (Goetz and Jenkins, 2005; Peruzzotti and Smulovitz, 2006; Joshi and Houtzager, 2012; Gaventa and McGee, 2013; Fox, 2015). Accountability, within this body of work, can be understood in relation to two dimensions. First, in line with Dreze and Sen's (1989) conceptualisation of public voice, social accountability is viewed as a politically motivated action by not just direct 
beneficiaries of public services, but also by different groups of civil society, as well as mediabased initiatives, involving the deployment of multiple strategies to hold powerful actors to account (Peruzzotti and Smulovitz, 2006, p. 3). Second, social accountability aims to challenge and counter the state's neglect of previously made promises. Joshi and Houtzager (2012) define it as citizens' actions to monitor the performance of duty-bearers, to seek justifications for unmet demands, and to protest when legitimate concerns are seen to be neglected. Protest, under this conceptualisation, is considered to be 'an especially vigorous form of voice' (Fox, 2015, p. 353).

\section{Study rationale and question}

It is increasingly acknowledged that humanitarian responders are subject to mounting pressures to perform, and to become accountable to multiple stakeholders (Bryant, 2007, p. 170; Taylor, Tharapos and Sidaway, 2014). They are expected to adhere to ever-burgeoning moral standards in the delivery of aid, while also attending to the newer forms of global governance standards concerning, for example, results and the cost-effectiveness of aid (Rubenstein, 2015). At the same time, public expectations within humanitarian crisis settings are taking complex forms (Donini and Walker, 2012), arguably posing challenges to and impacting on the aspirations and activities of those who perform on the frontlines.

Despite the fact that the humanitarian space is becoming increasingly contested through the involvement of newer actors such as individual volunteers, diaspora members, and activists (Hilhorst and Jansen, 2010; Sezgin and Dijkzeul, 2016), little is known about the consistency and inconsistency of accountability priorities and the pressures facing a mixture of formal and informal humanitarian entities. Engaging with the field-level experiences of early responders can yield invaluable insights into the hitherto under-examined topic of the politics of accountability in a disaster environment, while shedding light on the practical opportunities and difficulties associated with realising the longstanding yet disputed agenda of 'accountable humanitarian action'. Using the contested environment of Nepal's 'Great Earthquake' response as an empirical context, the current paper examines experiences of humanitarian accountability demands among early responders.

\section{Data sources: sampling techniques and interviews}

This study is situated in the interpretive and exploratory tradition of qualitative research, seeking to make sense of, or to interpret, phenomena concerning the meanings that people attach to them (Denzin and Lincoln, 2005, p. 3). To that end, in-depth interviews were 
conducted with a diverse sample of 15 early responders to the earthquake in Nepal in April 2015, who, owing to their social position or formal affiliation, were called upon to respond to the event. Employing a combination of purposive and snowball sampling techniques, participants were selected based on fulfilment of one of the following two criteria: (i) participation in rescue and relief efforts during the emergency response; or (ii) participation in planning and monitoring of the emergency response within the first three weeks of the earthquake.

The 15 interviewees had different backgrounds but all were involved closely in and/or had intimate knowledge of the emergency response. Two GoN representatives were interviewed, one of whom was closely involved in formulating the policy response to the earthquake, but had little prior experience from within the humanitarian or disaster sector; the second was a member of Nepal's national disaster relief network, who had previous experience of handling localised disaster responses and was closely involved in coordinating the earthquake response of governmental and non-governmental agencies. While government staff were difficult to recruit and thus few in number here, the two interviews are complemented by a review of key policy documents and media reports. Meanwhile, seven international aid workers were interviewed, of whom two were employed by bilateral aid agencies and five by INGOs. One of the bilateral aid agency workers had no experience of working on disaster management but was deployed to contribute to the high-level policy response following the earthquake, extending the study's information on governmental experience. The others had an assortment of experiences, serving as evaluators, implementers, and policy analysts. In addition, three interviews were held with members of Nepali civil society, who were engaged in monitoring the disaster response. Two of them had a background in Nepal's rights-based movement and one had experience of disaster preparedness and planning. Lastly, three youths/social activists were interviewed, who had an array of experiences of delivering and monitoring disaster response, but little to no prior involvement in formal humanitarian work. The interviewees were predominantly men (13); just two were women. All but one were Nepali nationals.

All of the interviews were conducted in Kathmandu in August-September 2015. Ethical approval of the study was secured from the London School of Economics and Political Science. Interviews lasted for approximately 60-90 minutes, and almost all of them were performed in Nepali; one international staff member of an INGO was interviewed in English. 
The interviewees were asked about the general context of the earthquake response, followed by enquiries pertaining to their specific involvement and experiences. Probing questions centred inter alia on specific controversies (such as the 'one-window policy)', local protests as reported by the media, and public concerns about transparency and corruption. Those representing the INGO and NGO communities were asked about their views on and experiences of implementing specific standards, practices, and tools of accountability. An open-ended question on the meaning and significance of accountability was put to all participants in the latter part of the interview.

\section{Analytical process}

The authors translated and transcribed all of the interviews. A thematic analysis was conducted to identify patterns (themes) within the data, following Attride-Stirling (2001) and Braun and Clarke (2006). Thematic coding of the interview transcripts was done in two phases: a set of descriptive codes was established first, followed by analytical codes that jointly revealed explicit and implicit ideas about the ways in which the participants experienced accountability demands. Specific themes were developed and identified via a literature review (see above) and inductively through coding and evaluation of the interview data. The final step entailed checking and organising the themes in relation to data extracts (Braun and Clarke, 2006). Throughout the process, reliability and rigour were accorded special emphasis, with the ongoing thematic analysis crosschecked against the original transcripts (Tobin and Begley, 2004).

\section{Findings}

The thematic analysis resulted in three different interpretations of accountability demands experienced by the participants: (i) accountability as compliance; (ii) accountability as the object of government regulation; and (iii) accountability as public opposition and interrogation. Each of the main themes and their sub-themes are discussed below. Interview quotations are used to represent better the voice of the participants. Their professional affiliation is indicated, as applicable. As per the study's ethical requirement, the identities of individual respondents are anonymised, but pseudonyms are used to describe the background and to add context to the quotations. 


\section{Accountability as compliance}

This refers to early responders' sense of duty to comply with accountability demands, and manifests through self-regulation according to personal values and aspirations and adherence to minimal protocols and standards of performance delivery.

\section{Compliance with ethical norms to respond to suffering}

Most interviewees said that self-directed and discretionary action characterised the early days after the earthquake. For most of the participants, the sight of widespread suffering prompted an immediate response. A youth activist, Bikram, described how he got involved in the rescue and relief efforts:

When I saw the devastation in Sankhu, tears ran down from my eyes. I wanted to do something but was not sure what to do. I had never seen an earthquake like this. Initially, I didn't know what to do. There was nothing to eat. We did whatever our heart asked us to do.

Bikram was driven by a moral obligation 'to do something' amidst his assessment of slow-moving rescue and relief initiatives. He immediately mobilised youth volunteers to clear up debris in one of the affected locations on the periphery of Kathmandu. Another civil society activist, Pramod, mentioned having an extreme form of 'restlessness' in the early hours of the earthquake. Like Bikram, he was concerned too about the seemingly slow and uneven aid distribution. He spearheaded a campaign to monitor the rescue and relief operations. Both Bikram and Pramod had no prior experience of humanitarian work or formal affiliation to the humanitarian sector, yet they engaged spontaneously in making the earthquake response ethical and effective, although with different aims and approaches.

Several interviewees echoed the view that compliance with ethical and normative standards depicted the initial phase of the government's response. The earthquake struck just before noon on Saturday, a public holiday. The first tremor was followed by continual aftershocks, which posed serious challenges to immediate rescue and relief endeavours. For Keshav, a government official associated with the National Disaster Relief Committee, this did not stop him from heeding the calls of public service. He remembered spending many sleepless nights working alongside senior government officials, responding to the requirements of national and international workers. 
Ashish, a local staff member with an international NGO, had professional experience of responding to localised disasters such as floods and landslides, but the demands and deprivation created by the earthquake were, for him, unparalleled. He stated that the early response was largely unplanned and entailed 'doing what was deemed possible at that stage'. The situation of uncertainty made it virtually impossible to distinguish victims from nonvictims, for instance, so relief was distributed to 'whoever sought help', in the words of Ashish. Despite mounting international efforts to codify minimum standards for accountable humanitarian action, interviewees perceived that quick action took priority over effective and targeted action initially following the earthquake.

\section{Compliance with international and national humanitarian protocols and frameworks}

The ethical urgency to respond was not the only form of compliance, however. Interviewees also recalled that various performance-based accountability measures to coordinate and regulate the performance of early responders taking effect at the national level. Notably, they emphasised the activation of the Natural Calamity (Relief) Act of 1982, a key policy intervention of the GoN (Government of Nepal, Ministry of Home Affairs and Disaster Preparedness Network-Nepal, 2013). The act, which came into existence in 1982 and has undergone several amendments, outlines the terms for declaring a national emergency, making the Ministry of Home Affairs the apex body in regulating and monitoring emergency activities. In addition, the legislation sets the terms for seeking assistance from the international community, making explicit the government's authority in approving the entry of international aid workers, directing them to specific disaster-struck areas, and gauging their performance.

Keshav mentioned that the activation of policy measures was done with bureaucratic precision: 'the systems got auto-activated'. Accountability as compliance also took the form of deregulatory measures, including waivers of visa conditions and custom duties, easing the inflow of aid workers and assistance items.

Several interviewees also drew attention to the importance of being attentive to internationally circulated guidelines and frameworks, such as the Core Humanitarian Standard on Quality and Accountability (CHS), the Hyogo Framework for Action (20052015), and Sphere guidelines. Furthermore, the activation of and participation in thematic cluster meetings (health and shelter), endorsed by the UN's Office for the Coordination of Humanitarian Affairs to ensure 'greater predictability, accountability and partnership' within a crisis context (UNOCHA, 2016), were also presented by many interviewees as moves to 
conform to globally circulated values of maintaining harmony and mutual accountability in the response. Although varied forms of formal, performance-centric accountability measures were 'auto-activated', their implementation at the field level was far from simple. The early phase following the earthquake was largely based, therefore, on 'doing what was deemed possible', as noted above.

\section{$\underline{\text { Compliance with an organisational mandate and performance standards }}$}

For many interviewees, particularly those representing mainstream NGOs, compliance also meant ensuring that their actions were consistent with the core mandate and mission of the concerned organisation. Ravi, a senior staff member with an international humanitarian NGO working in the area of food security, highlighted the avoidance of 'mission drift' as a critical measure of compliance-based accountability. In his line of work, this meant sticking with the fundamental objective of food distribution, and not over-reaching to address water and sanitation, for instance, because of emergency need.

As the earthquake response progressed, another area of compliance cited was adherence to everyday performance management standards. These are said to have been systematically inscribed into staff training programmes, monitoring and evaluation protocols, and processes. Mohan, a senior-level staff member with another global relief agency, underlined that: 'we also have the practice of providing orientation to our new staff. So, accountability is embedded in our orientation package'. Sama, an employee of another international NGO, equated accountability to a process of intra-organisational monitoring and sharing, with the 'programme quality' department maintaining scrutiny of the performance of different divisions. Being attentive to tools and practices, such as community-based grievance and feedback mechanisms, was emphasised, too. Mohan commented on how community feedback served as a vital instrument to 'set [a] quality benchmark' and 'rectify service delivery', while also helping to deter potential misconduct by personnel during aid operations. In a similar vein, needs assessment procedures, the selection and targeting of beneficiaries, and sharing information on proposed aid services with communities were pointed up as principal indicators of compliance.

The theme of 'compliance' here suggests that the initial days of the earthquake response were characterised, in large part, by a normative and self-directed mode of action, with minimal concern for the wider harmonisation or fairness of aid delivery. The GoN's regulatory measures were primarily limited to inviting, approving, and directing the entry of aid actors. However, as relief efforts progressed, myriad accountability-related protocols and 
practices are reported to have entered the emergency landscape, with the goal of injecting harmony and uniformity into the aid response. Although many of the international standards and codes are voluntary in nature, actors within mainstream humanitarian NGOs viewed them as practically binding. Early responders demonstrated knowledge of and commitment to international and organisational codes of conduct, together with the regulatory conditions set by the government. They were required to navigate through this expanding terrain of formal, performance-centric accountability measures, as discussed below, while also remaining vigilant to the urgent demands of those suffering owing to a major humanitarian emergency.

\section{Accountability as the object of government regulation}

This concerns the regulatory aim of the GoN, the source and nature of which may be traced to the coordination problems that emerged at the outset of the emergency response. The central government declared a state of emergency within 24 hours of the earthquake and appealed to the international community for immediate assistance. Its swift action, as well as its decision to relax visa conditions for international aid workers, enabled the early and easy arrival of humanitarian actors.

The influx of formal or mainstream NGO workers and informal actors (faith-based groups, foreign volunteers, and the Nepali diaspora), however, was described as unprecedented. Many had minimal in-country aid-related experiences, triggering coordination problems. By way of example, Nepal's only international airport, Tribhuvan in Kathmandu, was depicted as having become inundated with international rescue workers. This put further strain on the GoN's coordinating capacity and demanded reconfiguration of governmental logistical arrangements to deal with the growing demands of the many aid actors. Keshav, a government official involved in coordinating relief efforts, said:

There were foreigners all over. They would come asking me, 'where should we go?'. But I had to manage other things. Some of them were just sent to some (disaster-hit) districts, but they didn't find work and had to return. For some of them we had to create work.

Faced with increased pressures to manage the complex situation and to 'create work', together with a context lacking a clear framework of coordination and accountability, the government introduced regulatory measures.

\section{$\underline{\text { Regulation for regularity of aid }}$}


The GoN responded to the sense of uncoordinated aid with a series of measures, including streamlining the presence of aid actors in the field, wherein they were required to selfidentify the expertise and resources that they brought to bear. At the district level, relief efforts were expected to follow a memorandum of understanding with the chief district officer, specifying accounts of planned sites and specifics of aid delivery.

While the explicit logic of the early action by the government was to address the coordination problems, a more implicit logic encompassed its resolve to claim authority over the emergency response. Keshav explained:

In our [government's] global appeal which was placed on the foreign ministry website, we had asked the international community for what we needed. List of things were there. When they didn't come with those, we had the right to refuse the services. That was also treated as controlling. But we have the right to determine what we need and we can't allow everything to come in in the name of emergency.

For Keshav, the state of emergency should not allow aid workers to undermine the authority of the GoN, a view consistent with the Natural Calamity (Relief) Act of 1982. Several interviewees considered it to be normal, and to some extent desirable, for the government to assert its authority or to exercise its 'right to refuse' services in the emergency setting. Others, particularly those representing the international aid sector, likened the move to a historical pattern of behaviour of 'over-controlling' the entry and deployment of aid resources.

One regulatory framework to which reference was frequently made was the Development Cooperation Policy of 2014, which came into effect a year before the earthquake to regulate aid programmes in light of the chronic underperformance of the aid sector. The policy draws on international commitments such as the Paris Declaration on Aid Effectiveness (2005), the Accra Agenda for Action (2008), and the Busan Partnership for Effective Development Co-operation (2011), reiterating the principles of aid effectiveness, accountability, and transparency (Government of Nepal, Ministry of Finance, 2014). For the GoN, the influx of aid actors in the post-earthquake environment heightened existing concerns about 'fragmented' aid delivery and hence frustrated its efforts to augment the performance and effectiveness of development aid (Government of Nepal, Ministry of Finance, 2014, p. 6). The Development Cooperation Policy served as legitimate ground upon which aid actors were expected to 'adopt accountability in their process and to enhance 
transparency' (Government of Nepal, Ministry of Finance, 2014, p. 13), bolstering the government's determination to regulate the entry and involvement of aid workers.

The need for the GoN to assert a stronger monitoring and regulatory presence was also linked to what may be called 'role insecurity' among government officials. As public criticisms about the competency of the central administration in handling the situation were brewing nationally and internationally, government officials, in turn, were concerned that the non-governmental sector may be seen by the international donor community as an efficient and credible alternative for the transfer of aid, as had occurred in other disaster-struck countries, notably in Haiti after the earthquake on 12 January 2010 (Schuller and Morales, 2012). Khem, a bilateral aid agency staff member who worked closely with the government in preparing the emergency policy response, stated that senior officials within the government were concerned that they may have 'no role to play'. Another senior INGO staff member, Suraj, echoed this claim, adding that the government's sense of losing control over emergency efforts intensified a sense of 'competition' between government and INGOs, prompting closer monitoring of aid actors and the imposition of a regulatory order.

The expansion of the regulatory mode of accountability involved, among other instruments, the 'one-window policy'. This required that aid money should enter the country through a single, centrally-determined, government-mandated channel, thereby bringing nongovernmental actors within the purview of the government's monitoring apparatus. While the policy was justified through reference to the pre-existing policy environment, such as the Natural Calamity (Relief) Act and the Development Cooperation Policy, it was criticised extensively by the wider public for bureaucratising and slowing the distribution of aid. Here, as discussed below, the public strove to enact a public-centric form of accountability to temper the government's exertion of control.

\section{$\underline{\text { Regulation to manage future blame and criticism }}$}

A subtler form of regulatory accountability described by the early responders concerns the likelihood of long-term criticisms arising from unregulated emergency operations. This point needs to be located within the fraught political climate of Nepal. The earthquake struck the country at a time when the political atmosphere was far from favourable. Although Nepal had a democratically-elected government at the centre, the local governments lacked elected representatives and suffered from political fragmentation, which previous scholarship has noted as a major impediment to the effective delivery of development services and to holding local public officials to account (Tamang and Malena, 2011; Cima, 2013). In a country 
reeling from a decade-long (1996-2006) violent civil war between the GoN and the Communist Party of Nepal (Maoist), the political leadership was facing public resentment for having failed to promulgate a new constitution expected to set the course for reforms in relation to development and the public sector.

For many participants, the earthquake response had to be navigated vis-à-vis such a tense climate of public antipathy and a local democratic void. Bikram, a youth activist with a fleeting affiliation to a major political party, described how his aspiration to serve one of the hard-hit communities resulted in a near physical confrontation with community members. The conflict ensued because members of the affected communities considered, according to his reflection, his involvement to be 'politically motivated', to advance the interest of 'his political party'. The conflict had to be resolved through intervention by the local police. In another district where Bikram served, the volunteers had to be escorted out by government officials because the local communities opposed the way in which aid was distributed. In the absence of locally-elected representatives to facilitate the inflow of aid workers, the government bureaucrats had to be active in ensuring the coordination of aid workers, as well as the resolution of local disputes about aid distribution. 'That means the government resources were going to waste. There was no work being done', Bikram lamented. Such 'uncoordinated actions', in the mind of Bikram, and associated local tensions, were further bolstering the government's claim regarding the need to bring 'order' to the aid response.

Furthermore, reports of haphazard distribution of aid were widespread. Rajan, a human rights activist who participated in aid monitoring, termed it 'highway-based aid delivery', in which aid workers were mostly catering to communities easily accessible by road networks, while those inhabiting remote and inaccessible areas were generally being excluded. Stories about duplication of and disparity in aid efforts were circulating, prompting the government to monitor aid actors closely.

Interviewees also asserted that the government's move to instil harmony in aid delivery was intended to insulate it from blame and allegations in the future. Suraj, who participated in an NGO delegation to discuss problems and progress with relief initiatives, recalled a high-level government official in charge of overseeing the disaster response making the following point:

When you [I/NGOs] go and distribute those [zinc] sheets to the communities, would you say that the sheets also have contribution from the government? Government gave up tax revenue on that but when you distribute them, you would not give credit to us. Then the communities will blame us. They will 
say INGOs gave us zinc sheets but they [government] gave us nothing.

Being placed at the frontline, early responders found themselves subject to multiple and conflicting accountability demands from the government, which often had roots in the politically-charged climate of the emergency response. Such responders were not opposed to the formal, performance-centric accountability interventions, if they were directed at realising genuine coordination of relief activities, avoiding duplication of efforts, and ensuring fairness of aid distribution. However, interviewees viewed these criteria as missing, with the government narrowly concerned with wielding its regulatory power over aid actors, securing 'credit' for its action, and trying to protect itself from blame in the future.

\section{Accountability as public opposition and interrogation}

This refers to myriad forms of public opposition, disapproval, and scepticism confronting early responders, not just from members of affected communities, but also from the wider public.

\section{$\underline{\text { Public grievances about unmet material needs }}$}

Overall, participants described a fraught emergency environment, involving sharp public criticisms of both the GoN and aid actors. They described an assortment of reactions, ranging from sit-ins and public demonstrations in various places, to the blocking of roads and the transporting of materials destined for someplace else.

Gombu, another youth activist, pointed out that public grievances were attributed to material shortages, common when a large-scale disaster strikes a resource-constrained setting, and a sense of unfairness of aid distribution. He recalled:

\footnotetext{
In some cases, some people got certain type and quality of food, another group of people got something else. So that also led people to raise questions. At that time, it was impossible to control the aid distribution. Some relief agencies would distribute $25 \mathrm{~kg}$ [kilogrammes] of rice per household, others would do $10 \mathrm{~kg}$, some would give lentils, others would give oil. Some would give tents [for immediate shelter], and another would give tarpaulin, a simple one. That was another reason why people got angry.
}

Public criticism was also directed towards supply-driven, and de-contextualised aid efforts. Pramod, who led a campaign to monitor the immediate aid response, for instance, described one community's resistance to food aid when their priority was housing. As 
illustrated in the comment below, the public resisted the tendency of the aid actors to 'standardise aid delivery', without considering the local context and demands:

They did not have a problem of where to live. Lots of them are local and they had a place to live with their relatives and other community people. They also were not concerned about food. They could manage it on their own. They were mostly demanding immediate permanent housing. They were saying 'nobody talks about long-term housing. Don't come distributing food'. The houses there are historically congested and it was hard to remove the debris. So for them they were saying, 'we don't want food, please help us remove the debris. Help us build the houses'. So the issues and demands were quite diverse.

Interviewees representing mainstream humanitarian NGOs reflected how the implementation of accountability-related standards of quality and appropriate aid, inter alia, together with the application of tools and techniques proved unrealistic, and contentious. One salient example involved the introduction of a community-based needs assessment to distinguish 'fake' and 'genuine' victims, in relation to the distribution of cash assistance. The practices intended to ensure the quality of response and the suitability of aid recipients were portrayed as having been matters of intense negotiation, and even resistance, amidst the pressures to deliver quick-impact aid. Ravi, a staff member at a major bilateral aid agency working on food assistance, underlined that for desperate communities, a needs assessment and eligibility determination meant nothing but an unnecessary impediment to the immediate aid to which they felt entitled:

When I was in the field there was nothing. People were already starting to get angry. They did not want us to enter. 'What assessment are you going to do? There is no need for such assessment. Everything is gone here. We don't want you to find out how many people died and what we lost. Just bring us relief. Our immediate needs are food and shelter bring them to us'. They would say.

Consequently, the early responders faced an accountability dilemma. They were forced to strike a delicate balance between attending to communities' demands for the rapid delivery of aid (public-centric), while also complying with the organisational requirements surrounding proper identification of and ownership by beneficiaries (performance-centric).

\section{$\underline{\text { Accusations of historical neglect of disaster preparedness }}$}

Public opposition was also traced to the government's negligence in elevating the agenda and practice of disaster preparedness. Nepal's vulnerability to natural hazards and human-induced 
calamities, such as floods, glacier lake outbursts, landslides, and wildfires, is well established (Aryal, 2014). Even a senior government official, Rahim, admitted continual neglect of disaster planning and response: 'the government never invested in it'; it has 'petty policies, like rule books' to manage large-scale disasters.

Public criticisms coalesced around a pattern of the GoN treating disasters as naturally occurring, unexpected hazards that needed immediate attention, but abstaining from longerterm responsibility. Irfaan, who had longstanding experience of disaster management in Nepal, appreciated the instantaneous, moral logic that underpinned government action, but was critical of the government's tendency to shirk its obligation to provide for the long-term recovery needs of affected communities. In his words:

\footnotetext{
Clearly, if we look at government's role in light of the past few disasters, and specifically last one year of disaster history, whether we call Nepali government or Nepali state, it is not that they don't do immediate response. Even in floods, there is an incident, so local administration gets activated. There are security systems that get mobilised to rescue people and also some relief is provided. They give some immediate compensation to the victims and families of the deceased and also to the injured. Then things start to falter. State apparently thinks its responsibility has been discharged. When it comes to thinking of recovery, reconstruction or subsequent follow ups, nothing happens.
}

The pattern of assuming responsibility in the short term, and then desisting from it thereafter, was described as deeply embedded in the public psyche, generating further anxiety and questions about the future course of recovery from the earthquake.

Such negligence, lack of honest reflection, and a learning-based approach to disaster recovery also marred mainstream INGOs and NGOs. After offering a detailed account of Nepal's susceptibility to disasters triggered by natural hazards, Pramod, a civil society actor, reflected on how the aid sector has managed to escape responsibility for the sharing of information on its past achievements and failings:

In such kind of larger humanitarian crisis, what the government did, what NGOs did, what communities did, we don't know anything. We basically have no institutional memory of what happened and how it was responded to. There is nothing in public domain. That explains [why] we are so unaccountable towards what we do. That applies to both government and non-government actors.

Several respondents also underscored that the GoN's efforts during the emergency phase were excessively concerned with bringing coherence and discipline to the aid response, 
but lacked a healing and humane touch given that the public was reeling from a national tragedy. Rajan, a civil society activist who was engaged in monitoring relief distribution, gave a poignant account of how members of affected communities, who had assembled outside the district government office to question the reasons for ongoing delays in relief delivery, were shunned by the chief district officer (CDO):

\footnotetext{
Naturally people would come when they didn't get the relief. But the CDO would say 'why are you here? You are not supposed to be here'.
}

Instead of making efforts to listen to and engage with the grievances of affected communities, public officials were seen to have tried to maintain a 'safe distance' between citizens and government, triggering more opposition and anxiety among people.

\section{Criticisms of 'business as usual'}

Business as usual means the adoption of formal and ritualistic approaches to disaster response, ignoring calls for alternative and flexible initiatives. It also represents a lack of commitment by the GoN and aid actors to an open and transparent aid response, despite widespread calls for one. By way of example, the GoN used a centrally-located government system for humanitarian aid that was to be widely dispersed, applying the 'one-window policy' instrument (Giri, 2015; Paudyal, 2015). According to Irfaan, this move was widely resented, because the government was seen as neither competent nor trustworthy, given its poor record of effectively allocating, monitoring, and implementing regular development budgets:

Government doesn't have proper system and mechanisms. More so, government is not even capable of spending the budget. That is the reality. In such a situation, when the government says that the money has to be channelled through us, then people would obviously ask: what is going on?

The post-earthquake environment served as a space for civil society activists to pose uncomfortable questions about the pattern of aid interventions, which paid little attention to transparency of decision-making and budgeting and the deployment of experts and staff, among other things. These questions, as Pramod noted, 'were always there', indicating enduring public concern about the performance of aid actors. At a public event to disseminate lessons about the emergency response among the INGO sector, Suraj, a senior staff member 
who helped coordinate proceedings, recalled being challenged by a civil society activist to clarify public concerns regarding the budget and the overhead charges of INGOs:

Like some activists who worked as citizen volunteers raised questions about the large overhead that INGOs are criticised of spending. Like there was a question by one citizen group [informal aid actors] that they spent about one per cent of total budget as overhead but the INGOs are supposedly spending about 50 per cent as overhead. So those kinds of questions were asked.

For others, even prior to the earthquake, aid workers faced local scrutiny. '[We] are seen as experts in cultivating dollars, not results', Khem, an employee of a bilateral aid agency, reflected. However, communities' concerns became much starker following a large influx of foreign aid workers under the banner of emergency response. Ravi, a senior representative of an international humanitarian $\mathrm{NGO}$, mentioned how he had to confront questions from the public continually about the necessity of foreign workers and their value over national counterparts:

People would complain that there were lots of foreigners there, too; many consultants were brought in.

As the early responders scrambled to meet the needs of those affected by the disaster, they also described encountering public criticisms and critiques. Some of the reasons for such public scrutiny are linked to the service delivery gap that is characteristic of a high-impact crisis, whereas others are rooted in Nepal's fraught development history, characterised by longstanding grievances and doubts among aid-recipient communities about the capacity and integrity of the GoN and the aid community. The public-centric accountability demands, therefore, pertain not only to the appropriateness and fairness of the emergency response, but also to past experience concerning the role, responsibility, and performance of the government and aid workers.

\section{Conclusion}

Making humanitarian aid accountable to disaster-affected communities has long been a defining yet disputed topic within contemporary humanitarianism. Critics have called for a shift from an increasingly professionalised and performance-centric notion of accountability, to consideration of the political and contextual dynamics of humanitarian accountability (Stein, 2008; Barnett, 2013), yet little is known about the concrete forms of accountability 
demands experienced by early responders to humanitarian crises, and their implications for the practice of humanitarianism. Using the contested climate following the 'Great Earthquake' in Nepal in 2015, this paper has sought to advance understanding of the multiple accountability demands facing early responders in an emergency.

The paper shows that accountability during the early phase of the crisis assumed the form of internalised responsibility among early responders. Consistent with the core principle of humanitarianism that emphasises self-regulatory and ethical action (Slim, 2015), early responders' involvement was largely self-driven, 'to do something' to relieve the suffering of affected people. Although key policy and regulatory frameworks were activated immediately after the earthquake, they interfered minimally with the aspirations and activities of the early responders. The situation changed as the emergency response triggered a coordination problem, with the early responders having to navigate a complex terrain of formal accountability mechanisms introduced by the GoN and other relevant humanitarian organisations.

At the frontline of aid delivery, early responders' experience was characterised by what Bryant (2007) calls 'multidirectional', and oftentimes conflicting accountability demands. Frequently, these reflected broader political positions among disaster-affected populations, the national government, and the wider public.

Four fundamental points jointly underscore the tensions between performance-centric and public-centric accountability that frame the paper. First, existing literature on humanitarian accountability has focused principally on the performance and effectiveness of international NGOs, to the neglect of the accountability aspirations of the national government as a regulator and monitor of humanitarian responses (Stein, 2008). Despite facing an unprecedented disaster, the theme of 'accountability as the object of government regulation' highlights that the GoN was quick to prioritise 'order' and 'regularity' in the aid response, harnessing the accountability agenda and related notions of aid effectiveness, harmonisation and coordination of humanitarian aid (CHS Alliance, Group URD, and the Sphere Project, 2014; Government of Nepal, Ministry of Finance, 2014). Given the small number of interviewees from the government sector, this paper cannot claim to pinpoint the precise motives of the GoN and their consequences. However, it signals that such political drivers could be both historically-produced and disaster-related. The paper suggests that a fraught relationship between the GoN and non-governmental actors, coupled with growing public concern about haphazard aid distribution, further encouraged the government to monitor closely and regulate the conduct of early responders. In addition, its aspiration to 
ensure order in the emergency response, under the pretext of coordination and harmonisation, is also located within the perceived risk to the long-term legitimacy, image, and survival of the government in the wake of a major disaster (Boin, McConnell, and 't Hart, 2008). This has implications for the practice of early responders, as the internationally circulated value of 'right to provide assistance' in a crisis (Dufour et al., 2004) may come into conflict with, as this study shows, the government's assertion of a 'right to refuse' services. Beyond the current critiques of the accountability movement in the international humanitarian sector, attention should be paid in the future to the contextual and political dimensions of accountability, and more specifically to the regulatory standards introduced by national governments, which may have a bearing on the independence and performance of humanitarian responders.

Second, it is acknowledged that humanitarian responders are faced with increased demands for performance and accountability (Makuwira, 2006; Bryant, 2007; Taylor, Tharapos, and Sidaway, 2014). This paper takes a step forward in demonstrating a complex accountability environment in which early responders engage in humanitarian action. Not only are they expected to comply with the protocols and policies of the government, but also they are expected to address the criticisms of members of affected communities and the wider public. In such a context, adherence to the instrumental and technical version of accountability, such as a needs assessment to determine appropriate relief delivery, can come into conflict with heightened public demands for a speedy and fair response. The tension also exposes a gap in the current discourse of accountability that concentrates primarily on two forms of accountability demands: (i) accountability to donors; and, to a lesser extent, (ii) accountability to disaster-affected communities (Slim, 2015). As argued, accountability concerns within the mainstream humanitarian sector are mostly reduced to maintaining quality standards and exercising safeguarding measures, to avoid 'mission drift'. By contrast, engaging with or being responsive to accountability demands emanating from the public is overlooked. The paper contends that an emergency response to a humanitarian catastrophe is intrinsically linked to early responders' ability to appeal to, communicate with, and justify their actions to the wider public. Beyond performance and standards, paying sufficient attention to public demands is critical to enhancing early responders' accountability to communities in crisis, while also helping to build wider public acceptance of and confidence in the humanitarian community in general.

Third, previous research on multidirectional accountability has overlooked the accountability role of informal aid actors, or 'new humanitarians', whose increasing 
involvement reveals a changing and complicated landscape of humanitarian response (Hilhorst and Jansen, 2010; Sezgin and Dijkzeul, 2016). The engagement of early responders following the 'Great Earthquake' in Nepal was not limited to their traditional role of rescue and relief. As concerned members of the public, some were involved in scrutinising and auditing the emergency response, whereas others were part of the civil society advocacy coalition to influence the government's response more broadly. Still others spearheaded the monitoring of 'rights violations'. This paper emphasises the increasing diversity among early responders, whose engagement in a crisis context may contrast or even conflict with the roles of formal humanitarian actors, challenging the current discourse of accountability, which centres mostly on mainstream humanitarian actors. The mounting diversity of early responders also means that accountability-related concerns, aspirations, and responses are shaped by the positionality (that is, formal or informal standing, local or global affiliation, or social or political background) of individual responders. Future research should pay attention to the involvement of a wider network of aid workers, as well as their accountability aspirations and experiences with respect to humanitarian crises.

Fourth, as a major facet of accountability demands, public criticisms merit special attention. They are not to be dismissed as mere 'emotional outbursts' emanating from or on behalf of populations in distress. Rather, they are often crucial in challenging disaster responses that are divorced from local demands and preferences (Curato, Ong, and Longboan, 2016). This paper, drawing on the theory of public voice (Dreze and Sen, 1989) and recent advancements in the study and practice of social accountability (Joshi and Houtzager, 2012; Fox, 2015), casts a positive spotlight on the role of public criticisms that emanated in the wake of the earthquake response in Nepal. Beyond exposing the 'performance gap' in the delivery of humanitarian aid, the coalescing of public criticism bore both retrospective and prospective characteristics. The themes of 'historical neglect of disaster preparedness' and 'business as usual', for instance, represent the ways in which the public interrogated the disaster management capacity of state agencies and the transparency and results of aid interventions, among other issues. At the same time, the material disadvantage sparked by the earthquake, coupled with an unprecedented influx of aid resources and aid 'experts', provoked public concern about the ways in which aid resources are mobilised and allocated for recovery in the future. On the one hand, this suggests that public criticisms were not just a product of shortcomings of the emergency response, but also part of the historical mistrust and public scepticism facing authorities owing to misguided and exclusionary development efforts (Cima, 2013). On the other hand, the instrumental value of 
such criticism has important implications for the effectiveness of humanitarian practice, by commanding attention to immediate aid action, questioning over- or under-regulation of aid delivery, and early identification of a misguided aid response.

In sum, this paper asserts that accountability in a humanitarian context transcends the dominant understanding surrounding the management, effectiveness, and appropriateness of humanitarian performance. It is closely intertwined with humanitarian responders' sense of responsibility to attend to the demands of disaster-affected populations, while also navigating a wider set of demands from the public and national government. Such demands often have historical roots, but they also find a new impetus in the aftermath of a disaster. By providing concrete evidence of the multiple and politically-charged accountability demands confronting early responders, the paper seeks to elevate the significance of the public-centric approach to accountability in humanitarian emergencies, which has hitherto been marginalised by a narrower focus on performance-centric accountability.

\section{Acknowledgements}

An earlier version of the paper was presented at various academic meetings at the London School of Economics and Political Science; the paper benefitted significantly from the feedback of the attendees. In addition, the authors would like to thank the anonymous peer reviewers of this paper and the editorial staff for their insightful and constructive comments. Lastly, special thanks are extended to the study participants, who agreed to share and reflect on their experiences of having responded to the earthquake in Nepal.

\section{Correspondence}

Nimesh Dhungana, LSE Fellow in Qualitative Methods, Departments of Methodology and International Development, London School of Economics and Political Science, Houghton Street, London WC2A 2AE, United Kingdom. E-mail: N.Dhungana@1se.ac.uk 


\section{References}

Adhikari, P. (2015) 'Locals seize zinc sheets over discrepancy doubt'. The Kathmandu Post. 31 May. http://kathmandupost.ekantipur.com/news/2015-05-31/locals-seize-zincsheets-over-discrepancy-doubt.html (last accessed on 30 April 2020).

Aryal, K.R. (2014) 'Disaster vulnerability in Nepal'. International Journal of Disaster Risk Reduction. 9 (September). pp. 137-146.

Attride-Stirling, J. (2001) 'Thematic networks: an analytic tool for qualitative research'. Qualitative Research. 1(3). pp. 385-405.

Barnett, M. (2005) 'Humanitarianism transformed'. Perspectives on Politics. 3(4). pp. 723 740.

Barnett, M.N. (2013) 'Humanitarian governance'. Annual Review of Political Science. 16(1). pp. 379-398.

Boin, A., A. McConnell, and P. 't Hart (2008) 'Governing after crisis'. In A. Boin, A. McConnell, and P. 't Hart (eds.) Governing after Crisis: The Politics of Investigation, Accountability and Learning. Cambridge University Press, Cambridge. pp. 3-30.

Braun, V. and V. Clarke (2006) 'Using thematic analysis in psychology'. Qualitative Research in Psychology. 3(2). pp. 77-101.

Bryant, C. (2007) 'Evaluation and accountability in emergency relief'. In A. Ebrahim and E. Weisband (eds.) Global Accountabilities: Participation, Pluralism, and Public Ethics. Cambridge University Press, Cambridge. pp. 168-192.

Buchanan-Smith, M. (2003) How the Sphere Project Came into Being: A Case Study of Policy-making in the Humanitarian Aid Sector and the Relative Influence of Research. Working Paper 215. July. Overseas Development Institute, London. Change.org (2015) 'Nepal earthquake 2015 - petition to Transparency International, CIAA Nepal and United Nations'. https://www.change.org/p/nepal-earthquake-2015petition-to-transparency-international-and-united-nations (last accessed on 30 April 2020).

CHS Alliance, Group URD, and the Sphere Project (2014) Core Humanitarian Standard on Quality and Accountability.

https://corehumanitarianstandard.org/files/files/Core $\% 20$ Humanitarian $\% 20$ Standard $\%$ 20-\%20English.pdf (last accessed on 30 April 2020).

Cima, O. (2013) Accountability at the Local Level in Fragile Contexts: Nepal Case Study. IDS Working Paper 421. Institute of Development Studies, Brighton. 
Coyne, C.J. (2013) Doing Bad by Doing Good: Why Humanitarian Action Fails. Stanford University Press, Stanford, CA.

Curato, N., J.C. Ong, and L. Longboan (2016) 'Protest as interruption of the disaster imaginary: overcoming voice-denying rationalities in post-Haiyan Philippines'. In M. Rovisco and J.C. Ong (eds.) Taking the Square: Mediated Dissent and Occupations of Public Space. Rowman and Littlefield, London. pp. 77-96.

Daly, P. and C. Brassard (2011) 'Aid accountability and participatory approaches in postdisaster housing reconstruction'. Asian Journal of Social Science. 39(4). pp. 508-533.

Davis, A. (2007) Concerning Accountability in Humanitarian Action. Humanitarian Practice Network, London.

Denzin, N.K. and Y. Lincoln (2005) 'Introduction: the discipline and practice of qualitative research'. In N.K. Denzin and Y. Lincoln (eds.) The SAGE Handbook of Qualitative Research. Third edition. Sage Publications, Thousand Oaks, CA. pp. 1-32.

Donini, A. and P. Walker (2012) 'So what?'. In A. Donini (ed.) The Golden Fleece: Manipulation and Independence in Humanitarian Action. Kumarian Press, Sterling, VA. pp. 243-264.

Dreze, J. and A. Sen (1989) Hunger and Public Action. Clarendon Press, Oxford.

Dufour, C., V. de Geoffroy, H. Maury, and F. Grünewald (2004) 'Rights, standards and quality in a complex humanitarian space: is Sphere the right tool?'. Disasters. 28(2). pp. 124-141.

Everett, J. and C. Friesen (2010) 'Humanitarian accountability and performance in the Théâtre de l'Absurde'. Critical Perspectives on Accounting. 21(6). pp. 468-485.

Fernando, U. and D. Hilhorst (2006) 'Everyday practices of humanitarian aid: tsunami response in Sri Lanka'. Development in Practice. 16(3-4). pp. 292-302.

Fox, J.A. (2015) 'Social accountability: what does the evidence really say?'. World Development. 72 (August). pp. 346-361.

Gaventa, J. and R. McGee (2013) 'The impact of transparency and accountability initiatives'. Development Policy Review. 31(S1). pp. S3-S28.

Giri, A. (2015) “'Strict” one-window policy will ensure accountability: Govt'. The Kathmandu Post. 9 May. https://kathmandupost.com/miscellaneous/2015/05/09/strictone-window-policy-will-ensure-accountability-govt (last accessed on 30 April 2020).

Goetz, A. and R. Jenkins (2005) Reinventing Accountability: Making Democracy Work for Human Development. Palgrave Macmillan, New York, NY. 
Government of Nepal, Ministry of Finance (2014) Development Cooperation Policy, 2014: International Cooperation for Development Effectiveness. Government of Nepal, Ministry of Finance, Kathmandu.

Government of Nepal, Ministry of Home Affairs and Disaster Preparedness Network-Nepal (2013) Nepal Disaster Report 2013: Focus on Participation and Inclusion.

Government of Nepal, Ministry of Home Affairs and Disaster Preparedness NetworkNepal, Kathmandu.

Government of Nepal, National Planning Commission (2015) Nepal Earthquake 2015: Post Disaster Needs Assessment: Vol. A: Key Findings. Government of Nepal, National Planning Commission, Kathmandu.

Harris, G. (2015) 'Nepal's bureaucracy is blamed as earthquake relief supplies pile up'. The New York Times. 3 May. https://www.nytimes.com/2015/05/04/world/asia/nepalsbureaucracy-is-blamed-as-quake-relief-supplies-pile-up.html (last accessed on 30 April 2020).

Hilhorst, D. (2002) 'Being good at doing good? Quality and accountability of humanitarian NGOs'. Disasters. 26(3). pp. 193-212.

Hilhorst, D. and B.J. Jansen (2010) 'Humanitarian space as arena: a perspective on the everyday politics of aid'. Development and Change. 41(6). pp. 1117-1139.

Humanitarian Accountability Partnership (2010) The 2010 HAP Standard in Accountability and Quality Management. HAP International, Geneva.

Jalali, R. (2002) 'Civil society and the state: Turkey after the earthquake'. Disasters. 26(2). pp. 120-139.

Jayashi, D. (2015) 'Relief reaching only the influential: Nepal MP'. The Hindu. 19 May. https://www.thehindu.com/news/international/relief-reaching-only-the-influentialnepal-mp/article7224453.ece (last accessed on 30 April 2020).

Joshi, A. and P.P. Houtzager (2012) 'Widgets or watchdogs?: Conceptual explorations in social accountability'. Public Management Review. 14(2). pp. 145-162.

Keen, D. (2007) Complex Emergencies. Polity, Cambridge.

Krause, M. (2014) The Good Project: Humanitarian Relief NGOs and the Fragmentation of Reason. University of Chicago Press, Chicago, IL.

Makuwira, J. (2006) 'Aid partnership in the Bougainville conflict: the case of a local women's NGO and its donors'. Development in Practice. 16(3-4). pp. 322-333.

Middleton, N. and P. O'Keefe (1997) Disaster and Development: The Politics of Humanitarian Aid. Pluto Press, London. 
Mizohata, S. (2011) ‘Amartya Sen's capability approach, democratic governance and Japan’s Fukushima disaster'. The Asia-Pacific Journal: Japan Focus. 9(39). 28 September. Article ID 3648. https://apjjf.org/2011/9/39/Sachie-MIZOHATA/3648/article.html (last accessed on 30 April 2020).

National Human Rights Commission (2015) Preliminary Report on Monitoring on the Overall Human Rights Situation of Earthquake Survivors, Loss of Lives and Properties Including the Humanitarian Support such as Rescue and Relief Distribution Following the Massive Earthquake that Hit the Nation on 25th April, 2015. 21 May. http://www.nhrcnepal.org/nhrc_new/doc/newsletter/EarthquakeMonitoring\%20Pre-\%20English-Report\%202072.pdf (last accessed on 30 April 2020).

NGO Federation of Nepal et al. (2015) Joint Statement from Civil Society Organizations. 30 April. http://imadr.org/wordpress/wp-content/uploads/2015/05/Nepal_JointStatement-from-Civil-Society-Organizations_30April2015.pdf (last accessed on 30 April 2020).

Paudyal, L.M. (2015) 'From the horse's mouth'. My Republica. 8 May.

http://archive.myrepublica.com/2015-16/opinion/story/20641/from-the-horse-smouth.html (last accessed on 11 May 2020).

Pérouse de Montclos, M.-A. (2012) 'Humanitarian action in developing countries: who evaluates who?'. Evaluation and Program Planning. 35(1). pp. 154-160.

Peruzzotti, E. and C. Smulovitz (2006) ‘Social accountability: an introduction'. In E. Peruzzotti and C. Smulovitz (eds.) Enforcing the Rule of Law: Social Accountability in the New Latin American Democracies. University of Pittsburgh Press, Pittsburgh, PA. pp. 3-33.

Raju, E. and K. da Costa (2018) 'Governance in the Sendai: a way ahead?'. Disaster Prevention and Management: An International Journal. 27(3). pp. 278-291.

Roddy, S., J.-M. Strange, and B. Taithe (2015) 'Humanitarian accountability, bureaucracy, and self-regulation: the view from the archive'. Disasters. 39(S2). pp. S188-S203.

Rubenstein, J. (2015) Between Samaritans and States: The Political Ethics of Humanitarian INGOs. Oxford University Press, Oxford.

Schuller, M. (2012) 'Haiti’s bitter harvest'. In A. Donini (ed.) The Golden Fleece Manipulation and Independence in Humanitarian Action. Kumarian Press, Sterling, VA. pp. 171-196. 
Schuller, M. and P. Morales (2012) Tectonic Shifts: Haiti since the Earthquake. Kumarian Press, Sterling, VA.

Sen, A. (1999) Development as Freedom. Knopf, New York, NY.

Sezgin, Z. and D. Dijkzeu (2016) ‘Introduction: new humanitarians getting old?'. In Z.

Sezgin and D. Dijkzeul (eds.) The New Humanitarians in International Practice:

Emerging Actors and Contested Principles. Routledge, New York, NY. pp. 1-22.

Sharma, G. and R. Adkin (2015) 'Tired of waiting for aid, angry Nepalis block roads'.

Reuters World News. 29 April. https://www.reuters.com/article/us-quake-nepal-

collapse/tensions-rise-in-nepal-after-weak-response-to-deadly-quake-

idUSKBN0NI12120150429 (last accessed on 30 April 2020).

Siegler, K. (2015) 'Show us the aid: anger in an ancient Nepali town'. NPR. 1 May. https://www.npr.org/sections/goatsandsoda/2015/05/01/403533570/show-us-the-aidanger-in-an-ancient-nepali-town (last accessed on 30 April 2020).

Slim, H. (2002) By What Authority? The Legitimacy and Accountability of Non-governmental Organisations. Paper presented to the 'International Council on Human Rights Policy International Meeting on Global Trends and Human Rights: Before and After September 11', Geneva, Switzerland, 10-12 January 2002.

https://www.gdrc.org/ngo/accountability/by-what-authority.html (last accessed on 30 April 2020).

Slim, H. (2015) Humanitarian Ethics: A Guide to the Morality of Aid in War and Disaster. Oxford University Press, New York, NY.

Stein, J.G. (2008) 'Humanitarian organizations: accountable — why, to whom, for what, and how?'. In T.G. Weiss and M. Barnett (eds.) Humanitarianism in Question: Politics, Power, Ethics. Cornell University Press, Ithaca, NY. pp. 124-142.

Tamang, S. and C. Malena (2011) The Political Economy of Social Accountability in Nepal. Program for Accountability in Nepal. World Bank, Washington, DC.

Taylor, D., M. Tharapos, and S. Sidaway (2014) 'Downward accountability for a natural disaster recovery effort: evidence and issues from Australia's Black Saturday'. Critical Perspectives on Accounting. 25(7). pp. 633-651.

The Rising Nepal (2015) 'PM Koirala not to tolerate misuse of relief funds. 25 May. http://therisingnepal.org.np/news/3700 (last accessed on 30 April 2020).

The Sphere Project (2004) Humanitarian Charter and Minimum Standards in Disaster Response. The Sphere Project, Geneva. 
Tobin, G.A. and C.M. Begley (2004) 'Methodological rigour within a qualitative framework'. Journal of Advanced Nursing. 48(4). pp. 388-396.

Tong, J. (2004) 'Questionable accountability: MSF and Sphere in 2003'. Disasters. 28(2). pp. $176-189$.

United Nations Development Programme (2015) Supporting Nepal to Build Back Better: Key Achievements in UNDP's Earthquake's Response. October. United Nations Development Programme, Kathmandu.

United Nations Office for the Coordination of Humanitarian Affairs (2016) 'Coordination'. https://www.unocha.org/our-work/coordination (last accessed on 30 April 2020). 